Chlamydial infection is an important source of gynaecological morbidity, being commonly associated with acute and chronic pelvic inflammatory disease and therefore infertility. ${ }^{13}$ Both problems have a large impact on the provision of gynaecological services in a given area. Screening and treatment for chlamydial infection before transcervical instrumentation that breaches the internal cervical os may prevent iatrogenic pelvic inflammatory disease, ${ }^{14}$ especially when retained products of conception within the uterine cavity provide an ideal medium for bacterial growth. We think that in cases of termination of pregnancy our results justify prior screening for chlamydia in the west of Scotland and in other areas with similar prevalence rates. If screening facilities are lacking, prophylaxis may be justified. Screening has been endorsed by workers elsewhere in the United Kingdom. ${ }^{3}$

The high percentage of women with asymptomatic genital chlamydial infection makes the use of effective antibiotics-for example, a tetracycline or erythromycin-important in cases of pelvic inflammatory disease and suspected postpartum and postabortion endometritis. Treatment of the partners of patients with genital chlamydial infection is recommended in order to prevent reinfection and reduce the pool of genital chlamydial strains within the general population. For the gynaecologist this may entail shared management with the genitourinary physicians. In our study the prevalence of other sexually transmitted diseases was very low, which may reflect regional differences. This low prevalence, however, should not be regarded as unimportant.

We have detected a high incidence of chlamydial infection in both general practice and colposcopy clinics in Glasgow. General practitioners and gynae- cologists should be more aware of the importance of investigating and treating chlamydial infection in both asymptomatic women and their partners.

We thank Dr I Tait, of Glasgow Royal Infirmary, for advice and the staff of the colposcopy clinic and laboratories for their help.

1 Longhurst HJ, Flower $\mathrm{N}$, Thomas BJ, et al. A simple method for the detection of Chlamydia trachomatis infections in general practice. $\exists R$ Coll Gen Pract of Chlamydia trach

2 Krogh C, Van Kirk J. A study of routine gonorrhea cultures in a family practice. 7 Fam Pract 1987;24:597-600

3 Fish ANJ, Fairweather DVI, Oriel JD, Ridgway GL. Chlamydia trachomatis infection in a gynaecology clinic population: identification of high-risk groups and the value of contact tracing. European fournal of Obstetrics and Gynaecology 1989;31:67-74.

4 Ridgway GL, Mumtaz G, Stephens RA, Oriel JD. Therapeutic abortion and chlamydial infection. BMF 1983;286:1478-9.

Mills A. Therapeutic abortion and chlamydial infection. BMF 1983;286:1649.

6 Alberico S, Facca MC, Di Bonito L, Millo R, Casaccia R, Mandruzzato GP. Frequency of cervicovaginal infections in cervical intraepithelial neoplasia. Eur J Gynaecol Oncol 1988;9:252-7.

7 Wang S-P, Grayston T. Human serology in Chlamydia trachomatis infection with microimmunofluorescence. $\mathcal{F}$ Infect Dis 1974;130:388-97.

8 Bowie WR, Wang S-P, Floyd AJ, et al. Etiology of non-gonococcal urethritis: evidence for Chlamydia trachomatis and Ureaplasma urealyticum. $\mathcal{F}$ Clin Invest 1977;59:735-42.

9 Schacter J, Cles L, Ray R, Hines PA. Failure of serology in diagnosing chlamydial infection of the female genital tract. $\mathcal{F}$ Clin Microbiol 1979;10: $647-9$.

10 Aral SO, Holmes KK. Epidemiology of sexually transmitted diseases. In: Holmes KK, Mardh PA, Sparling PF, Weissner PJ, eds. Sexually Holmes KK, Mardh PA, Sparling PF, Weissner PJ,
transmitzed diseases. New York: McGraw-Hill, 1984:126-41.

11 Handsfield HH, Jarman LL, Roberts PL, et al. Criteria for selective screening for Chlamydia trachomatis infection in women attending family planning clinics. JAMA 1986;255:1730-4.

12 Wood PL, Hobson D, Rees E. Genital infections with Chlamydia trachomatis in women attending an antenatal clinic. Br $\mathcal{F}$ Obstet Gynaecol 1984;

13 Hare MJ. Pelvic inflammatory disease. BMF 1986;293:1225-8.

14 Southgate L, Treharne J, Williams R. Detection, treatment, and follow up of women with Chlamydia trachomatis infection seeking abortion in inner city general practices. BMF 1989;299:1136-7.

(Accepted l November 1990)

\title{
Ventilatory function as a predictor of fatal stroke
}

\author{
David P Strachan
}

Abstract

Objective-To investigate the relation between ventilatory function and subsequent mortality due to cerebrovascular disease.

Design-Prospective longitudinal study.

Subjects-A total of 18403 male civil servants aged 40-64 years at entry examination for the Whitehall study.

Main outcome measure-Mortality from cerebrovascular disease (ICD8 430-438) after 18 years of follow up.

Results-In all, 262 men with sinus rhythm at entry died due to stroke during the $\mathbf{1 8}$ years of follow up. Compared with men with a forced expiratory volume in one second of $\geqslant 3.5$ litres those with a value of $<3.0$ litres were almost twice as likely to die of cerebrovascular disease (rate ratio adjusted for age and systolic blood pressure $=1.88,95 \%$ confidence interval 1.32 to 2.69 ). This increased risk occurred within each tertile of systolic blood pressure. Nested case-control analyses were used to control precisely for confounding effects of age, height, and smoking (by matching) and employment grade and physiological risk factors (by modelling). The effect of forced expiratory volume in one second was independent of age, height, smoking habits, employment grade, blood pressure, weight, cholesterol concentration, glucose tolerance, electrocardiographic abnormalities, history of chest pain, and history of intermittent claudication.
Conclusions-Measurements of ventilatory function may assist clinical decisions about whether to treat mild hypertension. Impaired ventilatory function and stroke may share common causes.

\section{Introduction}

Reduced ventilatory function is a predictor of mortality due to cardiovascular causes and non-fatal coronary heart disease. ${ }^{1-8}$ Four studies have reported specifically the relation of ventilatory function to subsequent fatal ${ }^{6}$ or non-fatal ${ }^{259}$ cerebrovascular disease. An inverse association between spirometric indices and stroke was found in each case, although in none did it reach conventional levels of significance when adjusted for other risk factors.

This paper explores the relation between ventilatory function and mortality due to cerebrovascular disease among a cohort of middle aged civil servants who were followed up for 18 years. It also updates earlier findings from this cohort that related cardiovascular risk factors to fatal stroke. ${ }^{10}$

\section{Methods \\ STUDY POPULATION}

For the Whitehall study death certificates were obtained for 19018 male civil servants who were examined during 1967-9. ${ }^{.1}$ This analysis was limited to the 18403 men aged 40-64 years at examination and to deaths 
occurring on or before 31 January 1987 . The underlying cause of death was coded throughout according to the eighth revision of the International Classification of Diseases (ICD8).

The examination at entry ${ }^{11}$ included measurement of height, weight, and blood pressure (with the London School of Hygiene's sphygmomanometer with the subject seated). A six limb lead electrocardiogram was recorded and classified by the Minnesota code. ${ }^{12}$ Three forced expiratory manoeuvres were recorded with a Vitalograph spirometer and the mean values of the highest two measurements of forced expiratory volume in one second $\left(\mathrm{FEV}_{1}\right)$ and the corresponding measurements of forced vital capacity were entered into a computer for analysis. Subjects attended after an overnight fast, and capillary blood samples were collected two hours after a $50 \mathrm{~g}$ oral glucose load for measurement of blood glucose and cholesterol concentrations. The subjects were requested to complete a questionnaire, which included questions on lifetime smoking habits, employment grade, and history of cardiorespiratory symptoms. ${ }^{13}$

My analysis follows the conventions of previous reports $^{10}$ for classifying electrocardiographic abnormalities and blood glucose concentrations (details of these classifications are given as footnotes to table III).

\section{STATISTICAL ANALYSIS}

The statistical analysis system (SAS) ${ }^{14}$ was used for data processing, and statistical modelling was performed with the epidemiological graphics, estimation, and testing package (EGRET). ${ }^{15}$ Mortality among the whole cohort was analysed by log linear Poisson regression models and adjusted for age by fitting separate variables for each single year of age at examination.

More complex analyses including continuous variables were conducted by a "nested" (within the cohort) case-control approach. Cases were defined as men who died of cerebrovascular disease (ICD8 430-438) during the 18 years of follow up. Matched controls were selected for each case from among the men who survived longer than the subjects who died from the date of examination. The matching criteria were age at examination (single years), height (measured to the nearest half inch $(1.3 \mathrm{~cm})$ ), and smoking habit (never, former, or current smoker). All eligible controls were included, resulting in variable numbers of controls for each case.

The matched case-control sets were analysed by conditional logistic regression. Case-control state was the outcome variable, and measurements of ventilatory function and other cardiovascular risk factors were entered as explanatory variables. Coefficients from such regression models are equivalent to those obtained by proportional hazards regression ${ }^{16}$ and estimate the logarithm of the rate ratio per unit increase in an

TABLE I - Number of deaths due to cerebrovascular disease in a cohort of 18403 men during an average of $16 \cdot 6$ years of follow up by age at death and certified cause of death

\begin{tabular}{|c|c|c|c|c|c|c|c|}
\hline \multirow{2}{*}{$\begin{array}{l}\text { ICD8 } \\
\text { code }\end{array}$} & \multirow[b]{2}{*}{ Cause of death } & \multicolumn{5}{|c|}{ Age at death (years) } & \multirow{2}{*}{$\begin{array}{l}\text { Total included in } \\
\text { case-control } \\
\text { study }\end{array}$} \\
\hline & & $47-59$ & $60-64$ & $65-69$ & $70-74$ & $75-82$ & \\
\hline 430 & Subarachnoid haemorrhage & $10^{\star}$ & 7 & $9+\ddagger$ & 2 & 1 & 26 \\
\hline 431 & Cerebral haemorrhage & 125 & 14 & $10^{1+}$ & 10 & & 44 \\
\hline 432 & Occlusion of precerebral arteries & 1 & 1 & & 1 & & 3 \\
\hline 433 & Cerebral thrombosis & is & 2 & 6 & 12 & 6 & 26 \\
\hline 434 & Cerebral embolism & & & 1 & & & 1 \\
\hline 436 & Acute ill defined cerebrovascular disease & $8^{\star}$ & 175 & 429 & 41 & 36 & 140 \\
\hline 437 & Generalised ischaemic cerebrovascular disease & 1 & 1 & 4 & 89 & 3 & 16 \\
\hline 438 & Other and ill defined cerebrovascular disease & & 1 & 1 & 2 & 1 & 5 \\
\hline \multicolumn{2}{|c|}{ Total included in case-control study } & 29 & 42 & 69 & 74 । & 47 & 261 \\
\hline
\end{tabular}

The figures in the body of the table include the following subjects excluded from the case-control study: ${ }^{\star}$ one man with unknown smoking habit and $\mathrm{FEV}_{1}$; tone man with unknown blood pressure; ‡one man with no matching controls; Sone man with atrial fibrillation; lione man with no electrocardiogram; ๆ two men with atrial fibrillation. explanatory variable. In this instance these rate ratios are mortality ratios and are all adjusted for the matching variables (age, height, and smoking habit), in addition to other explanatory variables in the model.

\section{Results}

MORTALITY DUE TO STROKE IN COHORT

Of 18403 men aged $40-64$ at examination, 272 died of cerebrovascular disease during an average of 16.6 years of follow up. Table I shows the distribution of deaths due to stroke by age at death and certified underlying cause of death.

Six out of 69 men with atrial fibrillation at entry died compared with the figure of 1.3 expected deaths according to the age specific rates in the remainder of the cohort (rate ratio $4 \cdot 6 ; 95 \%$ confidence interval $2 \cdot 1$ to $10 \cdot 5)$. Inclusion of men with atrial fibrillation in subsequent case-control analyses resulted in failure to attain convergence in some of the models fitted. These six men and one other man whose electrocardiogram was not recorded at entry were therefore excluded from the remainder of the analyses.

Tobacco smoking at entry was associated with fatal stroke among men with sinus rhythm. The age adjusted rate ratios for current smokers compared with lifelong non-smokers were $1.38(95 \%$ confidence interval 0.96 to $2 \cdot 00$ ) for all deaths due to stroke, $2 \cdot 21$ ( 1.28 to $3 \cdot 84)$ for fatal strokes occurring before age 70 , and $0 \cdot 89(0.38$ to 2.08 ) for fatal strokes occurring after age 70 . The corresponding rate ratios for former smokers compared with lifelong non-smokers were $1.02(0.68$ to 1.48$)$, $1.59(0.89$ to $2 \cdot 82)$, and $0.64(0.37$ to $1 \cdot 10)$.

\section{CASE-CONTROL ANALYSES}

The case-control study was based on 261 patients and 3247 controls matched for age, height, and smoking habit. The number of controls ranged from one to 34 per case. In all, $111(43 \%)$ cases had fewer than 10 matched controls, but only $51(20 \%)$ had fewer than five matched controls. No controls could be matched to one man (height $152 \mathrm{~cm}$ ) who died of subarachnoid haemorrhage. Table I gives the other patients who were excluded because of missing data or atrial fibrillation at entry.

In single factor conditional logistic regression models fatal stroke was significantly more common among those with a low $\mathrm{FEV}_{1}$. The rate ratio per litre decrease in $\mathrm{FEV}_{1}$ (controlling for age, height, and smoking habit by matching) was $1.46(95 \%$ confidence interval $1 \cdot 16$ to $1 \cdot 84, \chi^{2}=10 \cdot 3, \mathrm{df}=1$ ). Inclusion of a quadratic term for $\mathrm{FEV}_{1}$ did not significantly improve the fit of the model $\left(\chi^{2}=1 \cdot 56, d f=1\right)$. The relation of forced vital capacity to death caused by stroke was of a similar strength (rate ratio $=1 \cdot 42$ /litre decrease, confidence interval $1 \cdot 13$ to $1 \cdot 80)$ but was less significant $\left(\chi^{2}=8 \cdot 68\right.$, $\mathrm{df}=1)$. There was a weak association between fatal stroke and the ratio of $F E V_{1}$ to forced vital capacity (rate ratio $=1.09$ per $10 \%$ decrease, 0.95 to 1.25 , $\chi^{2}=1 \cdot 42, \mathrm{df}=1$ ).

As expected, raised blood pressure was strongly related to mortality due to stroke. Taken individually, systolic blood pressure was a more powerful predictor of fatal stroke, as judged by the likelihood ratio statistic $\left(\chi^{2}=113 \cdot 7, \mathrm{df}=1\right)$ than was phase IV diastolic pressure $\left(\chi^{2}=92 \cdot 3, \mathrm{df}=1\right)$. When modelled jointly, however, the effect of diastolic pressure was significant $\left(\chi^{2}=7 \cdot 58\right.$, $\mathrm{df}=1$ ) after adjustment for systolic pressure. Quadratic terms for systolic $\left(\chi^{2}=3 \cdot 38, \mathrm{df}=1\right)$ or diastolic pressure $\left(\chi^{2}=2 \cdot 59, \mathrm{df}=1\right)$ did not significantly improve the model, but terms describing their interaction with age at death (above or below 70 years) were jointly significant $\left(\chi^{2}=7 \cdot 13, \mathrm{df}=2\right)$. Four terms were therefore used in subsequent analyses to adjust for the effects of blood pressure on mortality due to stroke: linear terms 
for systolic and diastolic pressure, each for deaths among men above and below 70 years of age.

When $\mathrm{FEV}_{1}$ was added to this model its effect was similar to that obtained before adjustment for blood pressure. The rate ratio/litre decrease in $\mathrm{FEV}_{1}$ was $1.41(95 \%$ confidence interval 1.12 to $1 \cdot 79)$, which remained highly significant $\left(\chi^{2}=8 \cdot 11, \mathrm{df}=1\right)$. Table II gives the rate ratios for blood pressure and $\mathrm{FEV}_{1}$ by age at death due to stroke. Although a low $\mathrm{FEV}_{1}$ was more strongly associated with fatal stroke occurring in men before age 70 than with deaths due to cerebrovascular causes in older men, the interaction between $\mathrm{FEV}_{1}$ and age at death was not significant $\left(\chi^{2}=2 \cdot 88, \mathrm{df}=1\right)$. There was no significant difference in the degree of association of reduced $\mathrm{FEV}_{1}$ with subarachnoid haemorrhage, cerebral haemorrhage, and other types of stroke $\left(\chi^{2}\right.$ for interaction $=3 \cdot 27, \mathrm{df}=2$ ). The effect of reduced $F E V_{1}$ was similar among current smokers, former smokers, and lifelong non-smokers $\left(\chi^{2}\right.$ for interaction $=2 \cdot 66$, $\mathrm{df}=2$ ). Further modelling therefore included only one

TABLE II - Rate ratio estimates ${ }^{\star}$ ( $95 \%$ confidence intervals) for fatal stroke associated with increase in blood pressure and decrease in FEV by age at death due to cerebrovascular disease

\begin{tabular}{lcc}
\hline & \multicolumn{2}{c}{ Age at death } \\
\cline { 2 - 3 } & $<70$ years & $\geqslant 70$ years \\
\hline $\begin{array}{c}\text { Systolic blood pressure } \\
\text { (per } 10 \mathrm{~mm} \text { Hg increase) }\end{array}$ & $1.31(1.17$ to 1.47$)$ & $1 \cdot 19(1.06$ to 1.34$)$ \\
$\begin{array}{c}\text { Diastolic blood pressure } \\
\text { (per } 10 \mathrm{~mm} \text { Hg increase) }\end{array}$ & $1.23(1.05$ to 1.46$)$ & $1.10(0.92$ to 1.33$)$ \\
FEV & (per litre decrease) \\
Number of cases/controls $\dagger$ & $1.71(1.24$ to 2.34$)$ & $1.13(0.79$ to 1.61$)$ \\
& $140 / 2193$ & $121 / 1054$ \\
\hline
\end{tabular}

* Mutually adjusted by conditional logistic regression.

†Matched for age, height, and smoking habit.

TABLE III - Rate ratio estimates ${ }^{\star}$ (95\% confidence intervals) for fatal stroke associated with various cardiovascular risk factors and rate ratio/litre decrease in $F E V_{l}$ before and after adjustment for each risk factor

\begin{tabular}{|c|c|c|c|c|}
\hline \multirow[b]{2}{*}{ Risk factor } & \multirow[b]{2}{*}{$\begin{array}{l}\text { Independent }{ }^{\star} \text { effect } \\
\text { of risk factor }\end{array}$} & \multirow[b]{2}{*}{$\chi^{2}(\mathrm{df}=1)$} & \multicolumn{2}{|c|}{ Rate ratio/litre decrease in $\mathrm{FEV}_{1}$} \\
\hline & & & $\begin{array}{c}\text { Before } \\
\text { adjustment } \dagger\end{array}$ & $\begin{array}{l}\text { After } \\
\text { adjustment }\end{array}$ \\
\hline Cigarette consumption (per 10 pack years) & $1.01(0.94$ to 1.09$)$ & $0 \cdot 10$ & $1 \cdot 40$ & 1.39 \\
\hline Employment grade $\neq$ ("low" $v$ "high") & $1.19(0.88$ to 1.59$)$ & $1 \cdot 26$ & 1.43 & 1.40 \\
\hline Body weight (per $10 \mathrm{~kg}$ increase) & $0.98(0.95$ to 1.01$)$ & $1 \cdot 19$ & $1 \cdot 41$ & 1.41 \\
\hline Plasma cholesterol (per $\mathrm{mmol} / \mathrm{l}$ increase) & $0.98(0.84$ to 1.15$)$ & 0.04 & $1 \cdot 38$ & $1 \cdot 38$ \\
\hline Blood glucose $\$$ (per $\mathrm{mmol} / \mathrm{l}$ increase) & $0.95(0.83$ to 1.08$)$ & $0 \cdot 72$ & $1 \cdot 42$ & $1 \cdot 43$ \\
\hline Glucose intolerance $₫$ ( $v$ normal tolerance $)$ & $0.97(0.53$ to 1.79$)\}$ & $0 \cdot 12$ & & \\
\hline Diabetes $\S$ ( $v$ normal glucose tolerance) & $1.18(0.44$ to 3.15$)\}$ & $(\mathrm{df}=2)$ & $1 \cdot 45$ & $1 \cdot 45$ \\
\hline History of angina (yes $v$ no) & $1.11(0.64$ to 1.94$)$ & 0.71 & $1 \cdot 43$ & $1 \cdot 42$ \\
\hline History of possible myocardial infarction & $1.07(0.63$ to 1.82$)$ & 0.07 & 1.43 & $1 \cdot 42$ \\
\hline History of intermittent claudication & $2 \cdot 19(1.00$ to $4 \cdot 74)$ & $3 \cdot 45$ & 1.42 & $1 \cdot 40$ \\
\hline Abnormal electrocardiogram & $1.35(0.88$ to 2.07$)$ & $0 \cdot 18$ & $1 \cdot 42$ & 1.41 \\
\hline
\end{tabular}

*Adjusted for age, height, and smoking habit by matching, and systolic blood pressure, diastolic blood pressure, and $\mathrm{FEV}_{1}$ by conditional logistic regression modelling.

tRate ratios before adjustment differ because of missing data for certain variables. Number of cases and controls varied from $261 / 3247$ for body weight to $252 / 3129$ for plasma cholesterol.

t"Low" grades - clerical and messenger grades; "high" grades-administrative, professional, and executive. Civil servants in the British Council and Diplomatic Service are excluded from these classifications

Blood glucose measured two hours after 50 g glucose lod Glucose the classications. Blood glucose measured two hours after $50 \mathrm{~g}$ glucose load. Glucose tolerance categories defined as "normal"below $95 \%$ centile point $(5 \cdot 4 \mathrm{mmol} / \mathrm{l})$; "intolerant" $-5 \cdot 4-11.0 \mathrm{mmol} / \mathrm{l}$; "diabetic" $-\geqslant 11 \cdot 1 \mathrm{mmol} / \mathrm{l}$. Previously

Minnesota codes for $\mathrm{Q} / \mathrm{QS}$ waves $(1 \cdot 1-1 \cdot 3)$, ST depression $(4 \cdot 1-4 \cdot 4)$, T wave inversion or flattening $(5 \cdot 1-5 \cdot 3)$, or left bundle branch block $(7 \cdot 1)$. term to describe the effect of $\mathrm{FEV}_{1}$ on mortality due to stroke.

The effect of other cardiovascular risk factors on the risk of fatal stroke and the association between low $\mathrm{FEV}_{1}$ and mortality due to stroke was investigated by adding them, in turn, to a "core model" consisting of the four blood pressure terms (shown in table II) plus $\mathrm{FEV}_{1}$. Table III shows the adjusted rate ratio estimates for each risk factor with associated $95 \%$ confidence intervals and likelihood ratio $\chi^{2}$ statistics. None of the risk factors were significantly associated with fatal stroke at the $5 \%$ level, although the rate ratio for history of intermittent claudication was of borderline significance $(p=0.06)$. The changes in the rate ratio for $\mathrm{FEV}_{1}$ when each cardiovascular risk factor was included in the model were small, indicating minimal confounding by these variables of the association between $\mathrm{FEV}_{1}$ and stroke (table III).

\section{CLINICAL PREDICTION OF FATAL STROKE}

The value of measurements of blood pressure and ventilatory function in clinically predicting fatal stroke was investigated among all men with sinus rhythm at entry. Table IV gives the mortality ratios (relative to 100 for all men) by tertiles of systolic blood pressure and tertiles of $\mathrm{FEV}_{1}$ (as measured), adjusting for age alone and for age, smoking habit, and employment grade.

In each third of the distribution of systolic blood pressure men in the lowest third of the distribution of $\mathrm{FEV}_{1}$ had higher age adjusted mortality due to stroke. The interaction between systolic blood pressure and $\mathrm{FEV}_{1}$ was not significant $\left(\chi^{2}=3 \cdot 56, \mathrm{df}=4\right.$, adjusting for age alone). Comparing men with $\mathrm{FEV}_{1}<3$ litres with those whose $\mathrm{FEV}_{1}$ was $\geqslant 3.5$ litres, the rate ratio adjusted for age (single years) and tertile of systolic blood pressure was 1.88 ( $95 \%$ confidence interval 1.32 to 2.69). After further adjustment for smoking habit and employment grade the corresponding rate ratio was $1 \cdot 70(1 \cdot 18$ to $2 \cdot 46)$.

A non-significant excess of deaths due to stroke remained among the current cigarette smokers, independent of age, employment grade, tertile of systolic blood pressure, and tertile of $\mathrm{FEV}_{1}$ (rate ratio $=1.32$ compared with lifelong non-smokers, $95 \%$ confidence interval 0.91 to 1.92 ). The rate ratio for men in "low" employment grades compared with those in "high" grades, adjusted for age, smoking, tertile of systolic blood pressure, and tertile of $\mathrm{FEV}_{1}$, was $1.20(0.92$ to 1.58$)$

\section{Discussion}

Recent reviews do not mention impaired ventilatory function as a possible risk factor for cerebrovascular disease..$^{178}$ The results presented here, considered alongside the findings of previous studies, ${ }^{2569}$ suggest that this may be an important omission. The association between spirometric indices and stroke can be con-

TABLE IV - Standardised mortality ratios ${ }^{\star}$ for cerebrovascular disease (adjusted for age alone and age, smoking habit, and employment grade) in men with sinus rhythm by tertiles of distribution of systolic blood pressure and $F E V_{1}$

\begin{tabular}{|c|c|c|c|c|c|c|c|c|c|}
\hline \multirow[b]{3}{*}{ Tertile of $\mathrm{FEV}_{1}$} & \multicolumn{9}{|c|}{ Tertile of systolic blood pressure } \\
\hline & \multicolumn{3}{|c|}{ Low $(<126 \mathrm{~mm} \mathrm{Hg})$} & \multicolumn{3}{|c|}{ Middle (126-142 mm Hg) } & \multicolumn{3}{|c|}{$\operatorname{High}(\geqslant 143 \mathrm{~mm} \mathrm{Hg})$} \\
\hline & Age alone & $\begin{array}{l}\text { Age, smoking } \\
\text { habit, } \\
\text { employment } \\
\text { grade }\end{array}$ & (Deaths) & Age alone & $\begin{array}{l}\text { Age, smoking } \\
\text { habit, } \\
\text { employment } \\
\text { grade }\end{array}$ & (Deaths) & Age alone & $\begin{array}{l}\text { Age, smoking } \\
\text { habit, } \\
\text { employment } \\
\text { grade }\end{array}$ & (Deaths) \\
\hline High $(\geqslant 3.51)$ & 21 & 22 & (5) & 52 & 55 & (13) & 127 & 135 & (26) \\
\hline Middle $(3 \cdot 0-3 \cdot 51)$ & 26 & 26 & (6) & 55 & 57 & (15) & 151 & 155 & (41) \\
\hline Low $(<3.01)$ & 63 & 60 & (20) & 115 & 109 & (41) & 201 & 194 & $(95) \dagger$ \\
\hline
\end{tabular}

${ }^{\star}$ Relative to standardised mortality ratio for all men $=100$. Adjusted by Poisson regression for: age at examination (single years), and age, smoking habit (never, former, current), and employment grade ("low," "high," unknown) 
firmed only by longitudinal studies as hemiparesis results in abnormalities of ventilatory function, ${ }^{19}$ which would invalidate a case-control comparison: Even a prospective design may, however, be susceptible to bias if subclinical cardiovascular disease results in poorer lung function. In the Framingham study reduced vital capacity seemed to be a sign of early congestive cardiac failure, but $\mathrm{FEV}_{1}$ did not show a similar association. ${ }^{20}$

This analysis was limited to deaths and therefore cannot distinguish between the effects of risk factors on incidence of disease and on case fatality. Short term survival after stroke is primarily determined by the severity of the stroke and the degree of comorbidity. ${ }^{21}$ Premorbid level of ventilatory function may influence case fatality, particularly among comatose patients. Reduced lung function may be a marker of physiological abnormalities which in turn predispose to stroke, such as polycythaemia ${ }^{22}$ or sleep apnoea. ${ }^{23}$ Alternatively, reduced $\mathrm{FEV}_{1}$ and fatal stroke may have environmental causes in common. Such causes may include heavy alcohol consumption, ${ }^{2+25}$ vitamin $\mathrm{C}$ deficiency, ${ }^{2627}$ or even air pollution. ${ }^{28}$ Early influences on the development of the lung may be implicated in the proposed link between the intrauterine environment and subsequent mortality due to stroke. ${ }^{29}$

The effects of current (but not former) cigarette smoking and the stronger influence of systolic than of diastolic blood pressure were both consistent with previous reports, ${ }^{30}$ although no dose-response relation was found among the smokers. The association of stroke with smoking was, however, largely independent of the reduced levels of ventilatory function among current smokers. The lack of association with plasma cholesterol concentration is consistent with previous studies, ${ }^{17}$ but this may conceal opposing trends for haemorrhagic and ischaemic strokes. ${ }^{32}$ There was no substantial increase in risk of stroke among diabetic patients when the effects of blood pressure were controlled in some detail. Other studies, however, have found an independent effect, ${ }^{334}$ and the confidence interval around the estimated rate ratio for diabetes is too wide to draw firm conclusions.

Identification and control of raised blood pressure is currently the main strategy for prevention of stroke. ${ }^{3 .}$ Under the common (but rarely tested) assumption that the relative benefits of treatment are the same for different patient groups greater absolute benefits may be expected for patients at higher underlying risk of disease. The balance of risks and benefits, and hence the choice of cut off at which to recommend pharmacological treatment, may therefore depend on levels of other risk factors for stroke. ${ }^{36}$ In this context measurements of ventilatory function may be more useful than many conventional cardiovascular risk factors for guiding clinical decisions about the management of patients with mild hypertension.

I thank Professor G Rose for encouraging me to analyse data from the Whitehall study and for his valuable comments.

1 Friedman GD, Klatsky AL, Siegelaub AB. Lung function and risk of myocardial infarction and sudden cardiac death. N Engl F Med 1976;294: $1071-5$.

2 Kannel WB, Hubert H, Lew EA. Vital capacity as a predictor of cardiovascular disease: the Framingham study. Am Heart f 1983;105:311-5.
3 Peto R, Speizer FE, Cochrane AL, et al. The relevance in adults of air-flow obstruction, but not of mucus hypersecretion, to mortality from chronic lung disease. Am Rev Respir Dis 1983;128:+91-500.

+ Kryzanowski $M$, Wysocki $M$. The relation of thirteen-vear mortality to ventilatory impairment and other respiratory symptoms: the Cracow studv. In f Epidemiol 1986;15:56-64.

5 Persson C, Bengtsson C, Lapidus L, Rybo E, Thiringer G, Wedel H. Peak expiratory flow rate and risk of cardiovascular disease and death: a 12-year follow-up of participants in the population study of women in Gothenbury, Sweden. Am 7 E:pidemiol 1986;124:942-8.

6 Farchi G, Menotti A, Conti S. Coronary risk factors and survival probability from coronary and other causes of death. Am $\mathcal{F}$ Eipidemiol 1987;126:400-8.

Cook $\mathrm{DG}$, Shaper AG. Breathlessness, lung function and risk of heart attack. Eur Heart f 1988:9:1215-22.

8 Ebi-Kryston KL, Hawthorne VM, Rose G, et al. Breathlessness, chronic bronchitis and reduced pulmonary function as predictors of cardiovascular disease mortality among men in England, Scotland and the United States. Int F Epidemiol 1989;18:84-8.

9 Welin L, Svardsudd K, Wilhelmsen L, Larsson B, Tibblin G. Risk factors for stroke in a cohort of men born in 1913. N Engl f Med 1987;317:521-6.

10 Fuller JH, Shipley MJ, Rose G, Jarrett RJ, Keen H. Mortality from coronary heart disease and stroke in relation to the degree of glycaemia: the Whitehall study. BMF 1983;287:867-70.

11 Reid DD, Brett GZ, Hamilton PJS, Jarrett RJ, Keen H, Rose G. Cardiorespiratory disease and diabetes among middle-aged male civil servants. A study of

12 Rose G, Baxter PJ, Reid DD, McCartney P. Prevalence and prognosis of electrocardiographic findings in middle-aged men. Br Heart $\mathcal{F}$ 1978;40: 636-43.

13 Rose G, McCartney P, Reid DD. Self administration of a questionnaire on chest pain and intermittent claudication. British fournal of Preventive and Social Medicine 1977;31:42-8.

14 SAS Institute. SAS user's guide: basics. Version 5. Cary, North Carolina: SAS Institute, 1985

15 Epidemiological Resources. EGRET: epidemiological graphics, estimation and testing. Seattle, Washington: Epidemiological Resources, 1988.

16 Breslow NE, Day NE. Statistical methods in cancer research. Vol 2. The design and analysis of cohort studies. Lyons: International Agency for Research on Cancer, 1987:204-6.

17 Dyken ML, Wolf PA, Barnett HJM, et al. Risk factors in stroke. A statement for physicians by the subcommittee on risk factors and stroke of the Stroke Council. Stroke 1984;15:1105-11.

18 Dennis MS, Warlow CP. Stroke. Incidence, risk factors and outcome. Br f Hosp Med 1987;37:194-8.

19 Fugl-Meyer AR, Linderholm H, Wilson AF. Restrictive ventilatory dysfunction in stroke: its relation to locomotor function. Scand $\mathcal{J}$ Rehabil Med 1983;9 (suppl):118-24.

20 Kannel WB, Seidman JM, Fercho W, Castelli WP. Vital capacity and congestive heart failure: the Framingham study. Circulation 1974;49: $1160-6$

21 Kelly-Hayes $M$, Wolf PA, Kannel WB, Sytkowski P, D'Agostino RB, Gresham GE. Factors influencing survival and need for institutionalisation following stroke: the Framingham study. Arch Phys Med Rehabil 1988;69:415-8

22 Marcus EB, Buist AS, Curb JD, et al. Correlates of $\mathrm{FEV}_{1}$ and prevalence of pulmonary conditions in Japanese-American men. Am Rev Respir Dis 1988;138: 1398-404

23 Kales A, Bixler EO, Cadieux RJ, et al. Sleep apnoea in a hypertensive population. Lancet 1984 ;ii: $1105-8$.

24 Hillbom ME. What supports the role of alcohol as a risk factor for stroke? Acta Med Scand 1987;717 (suppl):93-106

25 Lange P, Groth S, Mortensen J, et al. Pulmonary function is influenced bs heavy alchohol consumption. Am Rev Respir Dis 1987;137:1119-23.

26 Williams DRR. Diet and cerebrovascular disease. In: Smith A, ed. Recent advances in community medicine 3. Edinburgh: Churchill Livingstone, 1985:117-29.

27 Schwartz J, Weiss ST. Dietary factors and chronic respiratory disease. Am Rev Respir Dis 1989;139 (suppl):A28.

$28 \mathrm{Zhang} Z \mathrm{ZF}$, Yu SZ, Zhou GD. Indoor air pollution of coal fumes as a risk factor of stroke, Shanghai. Am F Public Health 1988;78:975-7.

29 Barker DJP, Osmond C, Law CM. The intrauterine and early postnatal origins or cardiovascular disease and chronic bronchitis. I Epidemiol Community Health 1989:43:237-40.

30 Shinton R, Beevers G. Meta-analysis of relation between cigarette smoking and stroke. BMJ 1989;298:789-94.

31 Kannel WB, Wolf PA. Epidemiology of cerebrovascular disease. In: RossRussell, ed. Vascular disease of the central nervous system. Edinburgh: Churchill Livingstone, 1983:1-2

32 Iso H, Jacobs DR Jr, Wentworth D, Neaton JD, Cohen JD. Serum cholesterol levels and six-year mortality from stroke in 350977 men screened for the multiple risk factor intervention trial. $N$ Engl f Med 1989;320:904-10.

33 Abbott RD, Donahue RP, MacMahon SW, Reed DM, Yano K. Diabetes and the risk of stroke. The Honolulu Heart Program. FAMA 1987;257:949-52.

34 Barrett-Connor E, Khaw KT. Diabetes mellitus: an independent risk factor for stroke? A $m$ f Epidemiol 1988;128:116-23.

35 Cutler JA, MacMahon SW, Furberg CD. Controlled clinical trials of drug treatment for hypertension. A review. Hypertension 1989;13 (suppl I) I36-44.

36 Browner WS, Hulley SB. Effect of risk status on treatment criteria. Implications of hypertension trials. Hypertension 1989; suppl I:I51-6.

Accepted I Novembir 1990 